\title{
The Threshold Effect of Regulatory Quality on the Relationship between Financial Development and Economic Growth: Evidence from Asian Countries
}

\author{
Gengnan Chiang ${ }^{1}$, Chin-Chi Liu ${ }^{2 *}$ and Hui-Hsuan $\mathrm{Liu}^{3}$
}

\begin{abstract}
This study aims to provide new insights on examining whether regulatory quality influences the relation between financial development and economic growth by applying a nonlinear panel smooth transition regression (PSTR) model. Using the data from Worldwide Governance Indicators (WGI) to assess the soundness of regulatory quality, this paper finds that the relationship between financial development, including life insurance and stock markets, and economic growth is significantly positive in the countries with relatively better regulatory quality. Our findings not only indicate that sound regulatory quality could encourage the growth effect of life insurance and stock market sectors but also have far-reaching practical implications for other economies to realize regulatory quality should matter for the development of economic growth.
\end{abstract}

JEL classification numbers: E44, G22, O11, O47, P34.

Keywords: Regulatory quality, Life insurance development, Stock market development, Economic growth, Nonlinear panel smooth transition regression (PSTR) model.

\footnotetext{
${ }^{1}$ Department of Finance, Feng Chia University, Taiwan.

$2^{2 *}$ Department of Finance, Ling Tung University, Taiwan.

${ }^{3}$ Department of Finance, Ling Tung University, Taiwan.
} 


\section{Introduction}

The role of an effective regulatory quality in promoting a country's economic and financial development has generated considerable interest among researchers and practitioners in recent years. However, only a few amounts of the existing literature have been devoted to understanding the effect of regulatory quality on financial development and economic growth. This study aims to investigate whether regulatory quality plays an important part in the nexus between financial development and economic growth by applying an innovative Panel Smooth Transition Regression (PSTR) model.

Prior literature shows that the impact of regulatory quality on financial development and economic growth is divergent. Some studies indicate that regulatory qualityrelated variables have a positive impact (Clague et al., 1997; Minier, 2003), while a negative influence is documented as well. Additionally, the existing empirical findings on the effect of regulatory quality on financial development and economic growth are mainly investigated in developed countries. It is interesting to explore whether regulatory quality shapes the relationship between financial development and economic growth in Asian countries.

In this study, we employ life insurance density and stock market activity as proxies for financial development, while we use the natural logarithm of annual real GDP per capita as a proxy for economic growth. Moreover, we utilize the data from Worldwide Governance Indicators (WGI) to assess the soundness of regulatory quality. The WGI is a long-standing research project to develop cross-country indicators of governance. Most importantly, these indicators are based on several hundred variables obtained from 31 different data sources, capturing governance perceptions as reported by survey respondents, non-governmental organizations, commercial business information providers, and public sector organizations worldwide. Regulatory quality in WGI is defined as capturing perceptions of the ability of the government to formulate and implement sound policies and regulations that permit and promote private sector development. The full sample dataset comprises a balanced panel of 11 Asian countries with a sample period from 2002 through 2017.

Additionally, this study proceeds with two steps to examine the effects of regulatory quality on the relationship between financial development and economic growth. First, we apply a threshold technique with the instrumental variables to endogenously divide countries into groups with different levels of regulatory quality. Second, we investigate whether the impact of regulatory quality on financial development varies under different levels of economic development. If exceptions do exist, then it may not be possible to form a consensus applicable to all countries. This would mean that certain conditions must be modified and that other preconditions be met before a country conforms to anyone's universal consensus.

Our main results demonstrate that the relationship between financial development and economic growth is significantly positive in countries with relatively better regulatory quality. More specifically, the result indicates that economic growth 
responds positively to financial development when the level of regulatory quality surpasses the threshold value of $47.67 \%$.

The empirical findings in this study make several contributions to the literature. First, comparing to prior studies that separately investigate the effect of regulatory quality on financial development (Ward and Zurbruegg, 2002; Beck et al., 2006; Lee et al., 2018) and the effect of financial development on economic growth (Hassan et al., 2011; Chen et al., 2012; Lee et al., 2016), we examine how regulatory quality shape the impact of financial development on economic growth by a novel dynamic panel threshold model.

Second, our findings further prove that a better regulatory quality indeed plays an important role in the relationship between financial development and economic growth. Specifically, a study that provides a clearer understanding of the relationship between financial development and economic growth in Asian countries will have important policy implications. Overall, the outcome sends strong signals to governments and administrations of countries in Asia regarding the importance of regulatory quality in the economy as well as improving financial development. Therefore, Asian countries should do everything possible to improve the regulatory quality framework and structures because better regulatory quality reduces the level of political turmoil, which is a great determinant of growth and investment.

The rest of this paper is as follows. Section 2 explains both the Moon and Perron unit root test and the primary structure of the PSTR model we apply in this research. Section 3 describes the data and variable selection. Section 4 presents our main empirical results of the PSTR model. Section 5 presents conclusions and further discussions.

\section{Literature Review}

The original debate on the relationship between financial development and economic growth can be traced to Schumpeter (1912), who argues that financial development contributes to economic growth through capital accumulation and technological innovations. More specifically, the well-developed financial system enhances capital formation and efficient resource allocation, which in turn triggers economic growth. Financial intermediaries are necessary for technological transformation and economic growth and development as their services monitor managers mobilize savings, manage risks, and facilitate transactions. Additionally, the sound financial market also helps in reducing the cost of borrowing money and that helps firms to propel their business (Rajan and Zingales, 1998).

Over the past decades, the connection between financial development and economic growth has attracted many concerns around the globe. The empirical evidence shows that financial development is positively associated with economic growth. For example, Ayadi et al. (2015) find a positive relationship between financial sector development and economic growth, utilizing a sample of northern and southern Mediterranean countries for the period 1985-2009. Dawson (2003) also 
shows that financial development, as measured by liquid liabilities as a proportion of gross domestic product, has a significant effect on economic growth, employing panel data on 13 Central and East European Countries (CEECs).

Additionally, previous studies also use private sector credit (PSC) provided by the banking sector as a prominent proxy variable for financial development and document the positive relationship between financial development and economic growth (Al-Jarrah et al., 2012; Hussain and Chakraborty, 2012; Hassan, Sanchez and $\mathrm{Yu}, 2011$; Inoubli, 2011; King and Levine, 1993). Another group of studies has used liquidity liabilities as one of the key indicators of financial development, and they show the positive and significant relationship between financial development and economic growth (Hassan et al., 2011; Jalil and Feridun, 2011). The stock market has been playing a tremendous role in financial sector development and has contributed to economic growth. Therefore, some researchers also have employed proxies along with the stock market as an indicator of financial development and have found that financial development and economic growth are positively related to each other (Chakraborty, 2010; Masoud and Hardaker, 2012 and Sahoo, 2013).

Despite all the above, there is not much literature that considers the role of regulatory quality between financial development and economic growth. In the past 20 years, however, the role of good regulatory quality for a country's development has been emphasized by policymakers and researchers. Prior studies show that regulatory quality indeed plays an important part in the finance-growth nexus (Lee et al. 2016). Authors such as Demetriades and Law (2006) suggest that variations in directions of causal relations often due to arise in finance-growth empirical studies are attributable to differences in the quality of regulations. Moreover, prior literature documents the role of regulatory quality in the nexus of financial development and economic growth in 21 Middle East and North African countries. Their findings show that financial development promotes economic growth only in countries with well-developed regulatory quality. Meanwhile, Demetriades and Law (2006) argue that competent and honest regulatory quality not only can productively mobilize human and physical resources in an economy but also leads to economic development because such quality mediates and signifies the momentum of economic growth. Additionally, Studies by Hajamini et al. (2014) consider regulatory quality as control variables when dealing with the financegrowth nexus. Their studies employed the GMM method and the fixed and random effects method respectively and realized that institutional quality, when coupled with financial development, increases growth. Most of the previous studies are concentrated on the developed nations, leaving the Asian economies unattended. This study, therefore, attempts to investigate the effect of financial development and economic growth in Asian countries considering the roles played by regulatory quality by applying a nonlinear panel smooth transition regression (PSTR) model to make policy recommendations. 


\section{Data and Methodology}

\subsection{Data}

This study adopts quantitative methods to investigate how regulatory quality affects the relationship between financial development and economic growth by applying an innovative panel smooth transition regression (PSTR) model. We examine the data set of 11 Asian countries from 2002 to 2017. The natural logarithm of real GDP (LRGDP) per capita indicates the country's level of economic growth and the natural logarithm of life insurance density (LLID) and stock market activity (LSPRICE) as proxies for financial development, the natural logarithm of the prices of common shares of companies traded on national or foreign stock exchanges, computed from the prices of selected stocks. The indicator is set as 100 in 2015 Prior researchers, such as Din et al. (2017) use annual real GDP per capita as a proxy for economic growth. Previous literature uses life insurance density as finance development indicators (Bick, 2010), while some researchers also have employed proxies along with the stock market activity as an indicator of financial development. The empirical studies have found that financial development and economic growth are positively related to each other (Chakraborty, 2010; Masoud and Hardaker, 2012 and Sahoo, 2013).

The data relating to life insurance density are collected from the base of Sigma SwissR data. It is the ratio of life insurance premium to the total population. Also, the data regarding the stock market activity are stocks traded total value in natural logarithm form. It is the total number of shares traded, both domestic and foreign, multiplied by their respective matching prices. The data are end-of-year values, includes companies admitted to listing and admitted to trading. The amount is single counted and only one side of the transaction is considered. The data of real GDP per capita is taken from the Organization for Economic Co-operation and Development and the World Bank Group. All variables are used in their natural logarithms.

To strengthen the reliability of evidence in this study, we add useful macroeconomic variables as control variables. Final consumption (FINCON) is defined as the sum of a household's final consumption expenditure and general government final consumption expenditure. Unemployment (UNEMP) is defined as the percentage of unemployed workers in the total labor force, and the unemployment rate is the number of unemployed divided by the number of the labor force in percentage. Long-term interest rates (LTINT) refer to government bonds maturing in ten years and to bonds whose capital repayment is guaranteed by governments. Inflation (INFL) is measured by the annual growth rate of the GDP implicit deflator displays the ratio of price varies within the economy as a whole. Gross fixed capital formations (FCAPITAL) comprise the inhabitant investments of producers and deducting disposals in fixed assets during a given period. These macroeconomic variables are also taken from the Organization for Economic Co-operation and Development and the World Bank Group. In this study, we utilize regulatory quality (RQ) as a transition variable in our PSTR model. Regulatory quality in WGI is 
defined as capturing perceptions of the ability of the government to formulate and implement sound policies and regulations that permit and promote private sector development.

Table 1 outlines the cross-sectional descriptive statistics for each variable in our study. It shows that the mean value of the natural logarithm of real GDP (LRGDP) of the overall sample countries is 9.02. Singapore has the highest value (10.62), while India has the lowest value (7.00). Also, the natural logarithm of average life insurance densities (LLID) of the overall sample countries in this study is 5.70. Both Japan and Hong Kong have better value than other Asian countries. They are 7.99 and 7.98, respectively. Moreover, Table 1 also indicates that the mean value of stock market activity (LSPRICE) of the overall sample countries is 4.22. Singapore has the highest value (4.50), while Indonesia has the lowest value (3.82).

We also observe that the highest average of regulatory quality (RQ) in our sample is Hong Kong (99.27). It implies that Hong Kong's sound legal environment provides a strong foundation for its free market, competitive economy. The lowest average of RQ in our sample is Indonesia (39.36). The mean value of regulatory quality (RQ) of the overall sample countries is 67.96.

Table 2 indicates the time-series variables descriptive statistics of 11 Asian countries from 2002 to 2017, where mean value only. According to this table, we find that the highest RGDP in 2017. Additionally, the value of average life insurance densities (LLID) is also increasing during the sample period. These figures imply that the relationship between life insurance development and economic growth is positive. Except for 2008 and 2009, the mean value of stock market activity (LSPRICE) also increasingly goes up. 
Table 1: Variable Cross-sectional Descriptive Statistics for 11 Asian Countries from Years 2002 to 2017

\begin{tabular}{|c|c|c|c|c|c|c|c|c|c|c|c|c|c|c|c|c|c|c|}
\hline \multirow{2}{*}{\begin{tabular}{|l} 
Variable \\
Country \\
\end{tabular}} & \multicolumn{2}{|c|}{ LRGDP, \$ } & \multicolumn{2}{|c|}{ LLID, \$ } & \multicolumn{2}{|c|}{ LSPRICE } & \multicolumn{2}{|c|}{ FINCON, \% } & \multicolumn{2}{|c|}{ UNEMP, \% } & \multicolumn{2}{|c|}{ LTINT, \% } & \multicolumn{2}{|c|}{ INFL, \% } & \multicolumn{2}{|c|}{ FCAPITAL, \% } & \multicolumn{2}{|c|}{ RQ, \% } \\
\hline & ean & $\mathrm{D}$ & ean & SD & & SD & & SD & Mean & SD & & SD & & SD & & D & in & SD \\
\hline Ching & & & & 78 & & 37 & & 38 & & 025 & & & & & & & & 02 \\
\hline & & & & & & & & & & & & & & & & & & 1.31 \\
\hline & & & & & & & & & & & & & & & & & & 25 \\
\hline & 年 & & 3.22 & 0.00 & & 0.84 & & 20.09 & 3.11 & 1.41 & & 2.42 & & 4.01 & & r. & (3.50 & .00 \\
\hline & 10.56 & & 7.99 & 4 & & 31 & & 2.13 & & 7 & & & & 112 & & U & & 78 \\
\hline & & & & & & 0.26 & & & & & & & & 2 & & & & 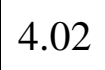 \\
\hline & & & 5.53 & 33 & & 0.34 & & .57 & & 0.23 & & 0.41 & & 3.90 & & U & & 4.47 \\
\hline & & & & & & 0.65 & & & & & & & & & & & & 3.35 \\
\hline Singapore & 0.62 & & 7.68 & & & 0.29 & & 3.01 & & & & & & 2.20 & & .90 & & 1.09 \\
\hline & 81 & & 7.75 & 0.43 & & 0.20 & & 1.25 & & 0.65 & 1.79 & 0.65 & 1.03 & 0.96 & & 1.82 & & 4.62 \\
\hline Thailand & 36 & & 4.66 & 0.66 & .33 & 0.44 & & 121 & 105 & 0.42 & 3.82 & 1.07 & 2.74 & 1.54 & & .59 & 9.74 & 2.92 \\
\hline All & & & .70 & 05 & 22 & 52 & 0.74 & 4.57 & 3.83 & 1.38 & 4.29 & 2.82 & 2.88 & 3.48 & 1.08 & .17 & 7.96 & 21.7 \\
\hline
\end{tabular}


Table 2: Variable Time-series Descriptive Statistics for 11 Asian Countries from Years 2002 to 2017

\begin{tabular}{|c|c|c|c|c|c|c|c|c|c|c|c|c|c|c|c|c|c|c|}
\hline Vari & & & & & & & FI & & ON & & & & INI & & FO & $\%$ & & \\
\hline Year & Mean & SD & Tean & SD & Tean & SD & Mean & SD & Mean & SD & Mean & SD & Mean & SD & Mean & SD & Iean & SD \\
\hline 2002 & & & & & & & & (3) & & & & 0.03 & $1.4 J$ & $2.0+$ & & .71 & & 0.13 \\
\hline 0 & & 51 & 5.00 & 231 & ( & 4 & & 27 & & 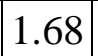 & & 1 & 1.52 & J & & 1 & & 24 \\
\hline 200 & & 0 & 5.14 & .01 & $J$ & & & 59 & & 3 & 5 & 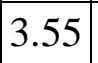 & 0 & 0.50 & & 01 & 8 & 5.00 \\
\hline 2 & 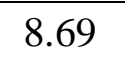 & 1 & 5.25 & | & 3.87 & 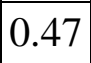 & 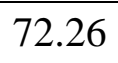 & 328 & 4.38 & & & 366 & 4.20 & 10 & & 5 & & 2305 \\
\hline 2006 & & 42 & 41 & 2.21 & 4.11 & 41 & 69.74 & .41 & $U$ & 40 & .75 & 2.59 & 3.60 & 4.2 & 26 & .87 & .34 & 20.97 \\
\hline 2007 & 801 & 33 & 563 & 211 & 41 & 6 & 7 & 3 & 3.87 & 51 & 101 & 52 & 4 & 327 & & 0 & 8 & 2121 \\
\hline 2008 & 99 & 31 & 5.57 & .16 & 4.03 & 35 & 69.10 & 2.89 & 3.97 & .45 & 4.05 & 3.18 & 5.68 & 5.7 & 27.16 & 5.36 & 7.34 & 21.10 \\
\hline 2009 & 000 & 20 & 5.68 & 2.05 & 4 & 0 & (5) & 2 & 4.30 & 1.21 & 0 & 2.05 & 3 & 0 & 21.7 & 0 & 1 & 4 \\
\hline 2010 & 16 & .26 & 5.86 & 1.99 & 4.37 & .23 & 67.72 & 9.96 & 3.87 & 1.38 & 4.17 & 2.24 & 4.49 & 4.92 & 27.45 & 7.24 & .68 & 23.42 \\
\hline 2011 & 20 & $1.2 \mathrm{~J}$ & 5.96 & 1.98 & 4.36 & 0.20 & 00.02 & 1.01 & 3.54 & 1.11 & $5.0 J$ & 2.01 & 3.90 & J.2J & 27.48 & 7.37 & 6.61 & 22.34 \\
\hline 2012 & 30 & 124 & 6.05 & \begin{tabular}{|l|}
108 \\
\end{tabular} & 4.43 & .27 & 68.59 & 6.40 & 347 & 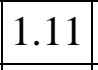 & 3.22 & 221 & .27 & 2.2 & 28.21 & 7.05 & 25 & 23.05 \\
\hline 2013 & 32 & 1.22 & 6.08 & 1.93 & 4.49 & 0.20 & 69.22 & 7.48 & 3.3 & 1.10 & 4.04 & 2.56 & 1.86 & 2.06 & 66 & 6.80 & .59 & 22.83 \\
\hline 2014 & T & 1.21 & 6.12 & 1.96 & 4.58 & 0.19 & 70.54 & 2.72 & 5.20 & 1.03 & 3.61 & 2.31 & 2.09 & 1.58 & & 6.70 & 0.41 & 22.97 \\
\hline 2015 & & 1.20 & 6.14 & 1.93 & 4.61 & 0.00 & 71.49 & .30 & & 1.10 & 3.48 & 2.65 & .56 & 1.77 & & 5.31 & 70.72 & 22.43 \\
\hline & & 1.20 & 6.21 & 1.94 & 4.58 & 0.09 & & 36.70 & & 1.05 & 3.31 & 2.37 & 1.64 & 1.00 & & 5.98 & 71.46 & 22.20 \\
\hline 2017 & 9.41 & 1.18 & 6.31 & 1.91 & 4.74 & 0.13 & 72.12 & 40.24 & 3.15 & 1.03 & 3.35 & 2.30 & 2.43 & 1.40 & 27.31 & 5.92 & 72.16 & 21.28 \\
\hline All & 9.02 & 1.31 & 5.70 & 2.05 & 4.22 & 0.52 & 70.74 & 34.57 & 3.83 & 1.38 & 4.29 & 2.82 & 2.88 & 3.48 & 27.08 & 6.17 & 67.96 & 21.76 \\
\hline
\end{tabular}




\subsection{Moon and Perron unit root test}

To make sure all variables in the panel of this study are stationary before exercising the PSTR model, we initially execute Moon and Perron unit root test that was developed by Moon and Perron (2004). Among the panel unit root tests, Bai and Ng (2004) supplied an intact program to examine the degree of integration of series, and permit tests for unit roots in the common factors and characteristic factors. Moon and Perron (2004) used a factor structure to simulate cross-sectional dependence, and used a normal autoregressive procedure with fixed effects, that residuals follow a factor model. They stated that their intention for these de-factored data is similar but still account for multiple common factors, in which the model is slightly different from Bai and Ng's (2004). Moon and Perron (2004) considered that the error terms are produced with $\mathrm{r}$ common factors and idiosyncratic shocks, with the same symbol as before, since the model can be written:

$$
\begin{aligned}
& y_{i t}=\alpha_{i}+y_{i t}^{0} \\
& y_{i t}^{0}=\rho_{i} y_{i, t-1}^{0}+\mu_{i t} \\
& \mu_{i t}=\lambda_{i}^{\prime} F_{t}+e_{i t}
\end{aligned}
$$

Where the null hypothesis corresponds to the unit root hypothesis $\mathrm{H}_{0}: \rho_{\mathrm{i}}=1, \quad \forall_{\mathrm{i}}=$ $1, \ldots ., \mathrm{N}, \lambda_{\mathrm{i}}$ is a vector of factor loadings, $\mathrm{F}_{\mathrm{t}}$ is a $\mathrm{r} \times 1$ vector of common factors and the idiosyncratic component $e_{i t}$ is assumed to be i.i.d., across $i$ and over $t$. Whereas under the alternative the variable $y_{i t}$ is stationary for at least one cross-sectional unit. These examination processes include two steps, the first step, the data are decomposed, and in the next step, the panel unit root test statistics depend on decomposed data and common factors are then raised. We want to know whether the factor structure permits clear-cut conclusions about the stability of macroeconomic variables.

Moon and Perron (2004) want to remove the common factors, thus, the panel data must be projected onto the space orthogonal to the factor loadings, the de-factored residual, and the de-factored data no more possess cross-sectional dependencies. They process the factors as nuisance parameters and suggest pooling de-factored data to construct a unit root test. It is probable to define standard pooled t-statistics, like in IPS, and to display their asymptotic normality. Since let $\hat{p}_{\text {pool }}^{+}$be the modified pooled OLS estimator applying the de-factored panel data. Two modified $\mathrm{t}$-statistics have a standard normal distribution under the null hypothesis following:

$$
t_{a}=\frac{T \sqrt{N}\left(\hat{p}_{\text {pool }}^{+}-1\right)}{\sqrt{2 \gamma_{e}^{4} / \omega_{e}^{4}}} \underset{N, T \rightarrow \infty}{\longrightarrow} N(0,1)
$$




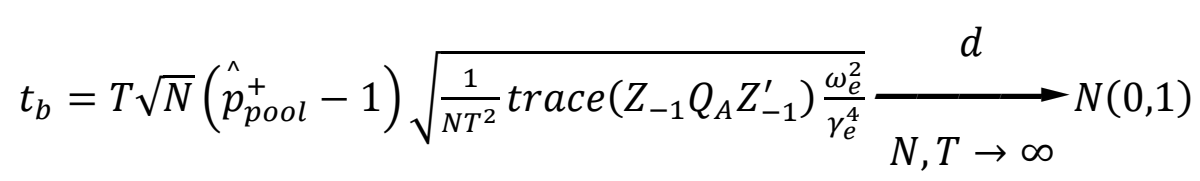

Where $\omega_{e}^{2}$ is the cross-sectional average of the long-run variances $\omega_{e i}^{2}$ of residual $e_{i t}$, $\gamma_{e}^{4}$ is the cross-sectional average of $\omega_{e i}^{4}$. And they raise feasible statistics $t_{a}^{*}$ and $t_{b}^{*}$ based on the estimator of the projection matrix and estimators of long-run variances $\omega_{e i}^{2}$.

\subsection{Panel smooth transaction regression model}

The PSTR model proposed by González et al. (2005) is to be considered as the most recent extension STR model on panel data with heterogeneity among the panel members and throughout time. The underlying PSTR model consists of a single transition function and two extreme regimes that can be described as follow:

$$
y_{i t}=\mu_{i}+\beta_{0}^{\prime} X_{i t}+\beta_{1}^{\prime} X_{i t} \mathrm{~g}\left(q_{i t} ; \gamma, C\right)+\varepsilon_{i t}
$$

where $i=1, \cdots, \mathrm{N}, t=1, \cdots, \mathrm{T}$. Specifically, $\mathrm{N}$ and $\mathrm{T}$ present the cross-section and time dimensions of the panel, respectively. The dependent variable $y_{i t}$ is a scalar; $\mu_{i}$ means the fixed individual effect; $X_{i t}$ is a k-dimensional vector of time-varying exogenous variables; and $\varepsilon_{i t}$ is the residual term. The transition function $\mathrm{g}\left(q_{i t} ; \gamma, C\right)$, a continuous function of the observable variable $q_{i t}$, is normalized to be bounded between 0 and 1 ; these extreme values are associated with regression coefficients $\beta_{0}^{\prime}$ and $\beta_{0}^{\prime}+\beta_{1}^{\prime}$. The vale of $q_{i t}$ determine the values of $\mathrm{g}\left(q_{i t} ; \gamma, C\right)$, and thus the effective regression coefficient is $\beta_{0}^{\prime}+\beta_{1}^{\prime} \mathrm{g}\left(q_{i t} ; \gamma, C\right)$ for individual $i$ at time $t$. Following the method proposed by Granger and Teräsvirta (1993), we expressed the transition function as follows:

$\mathrm{g}\left(q_{i t} ; \gamma, C\right)=\left(1+\exp \left(-\gamma \prod_{j=1}^{m}\left(q_{i t}-c_{j}\right)\right)^{-1}\right.$ with $\gamma>0$ and $C_{1} \leq C_{2} \leq \cdots \leq C_{m}$

where $C=\left(C_{1}, \cdots, C_{m}\right)^{\prime}$ is an $m$-dimension vector of location parameters and the slope parameter $\gamma$ determines the smoothness of the transaction. In general, considering $m=1$ or $m=2$ is sufficient, because these values allow for typically encountered variations in the parameters. In the case of $m=1$, the model identifies that the two extreme regimes are associated with low and high values of $q_{i t}$ and that a single monotonic transition of the coefficients exists from $\beta_{0}^{\prime}$ to $\beta_{0}^{\prime}+\beta_{1}^{\prime}$ as $q_{i t}$ increases, such that the change is centered near $C_{1}$. In the case of $\mathrm{m}=2$, the minimum of the transition function is at $\left(C_{1}+C_{2}\right) / 2$ and achieves the value one at the low and high values of $q_{i t}$. When $\gamma$ approaches infinity, the PSTR model reduces to a three-regime panel threshold regression PTR model the outer regimes of which are identical to each other but different from the middle regime.

The multi-level PSTR model is a generalized PSTR model that allows for more than 
two different regimes; it can be expressed as follows:

$$
y_{i t}=\mu_{i}+\beta_{0}^{\prime} X_{i t}+\sum_{j=1}^{r} \beta_{1}^{\prime} X_{i t} \mathrm{~g}_{j}\left(q_{i t}^{j} ; \gamma_{j}, c_{j}\right)+\varepsilon_{i t}
$$

where the transition function $\mathrm{g}_{j}\left(q_{i t}^{j} ; \gamma_{j}, c_{j}\right), j=1, \cdots, r$ depends on the slope parameters $\gamma_{j}$ and on the location parameters $c_{j}$. If $\mathrm{r}=1, q_{i t}^{j}=q_{i t}$, and $\gamma_{j} \rightarrow \infty$ for all $j=1, \cdots, r$, the transition function becomes an indicator function, in which $\mathrm{I}[A]$ $=1$ when event A occurs, and $\mathrm{I}[A]=0$ otherwise; the model in Eq. (4) becomes a PTR model with $r+1$ regimes. Consequently, the multilevel PSTR model is a generalization of the multiple regimes PTR denoted by Hansen (1999).

\subsection{Building the panel smooth transition regression model}

Building the panel smooth transition regression model requires three stages, such as specification, estimation, and evaluation. The specification stage includes testing for homogeneity and choosing the transition variable $q_{i t}$. If the testing fails to exhibit homogeneity, specification covers determining the appropriate form of the transition function; this form is described by the value of $m$ in Eq. (3). A nonlinear least square method is used to estimate parameters. On the estimation stage, the estimated model is restricted to misspecification tests to determine whether adequate data description is provided. The null hypotheses tested in this stage contain parameter constancy, the absence of remaining heterogeneity, and the absence of autocorrelation among the errors. In the last stage, the number of regimes in the panel must be specified, implying that value has to be assigned to $r$ in Eq. (4).

\section{Estimation Results and Interpretations}

The number of common factors $r$ is estimated for each variable in table 3. Unlink Bai and Ng (2004), Moon and Perron (2004) used $\hat{y}$ as residuals and the information criteria are calculated from demeaned first differences. Similarly, we calculate two statistics $t_{a}^{*}$ and $t_{b}^{*}$ with Bartlett and Quadratic Spectral kernel after assessing the sensitivity of our results to the choice of the kernel function used to estimate $\omega_{e i}^{2}$. In this case, bandwidth parameters are optimally chosen according to the procedure of Ayram et.al. (2010). And the results for a model with time trends are replied. We employ the same criteria to appraise the number of common factors as if this model only has individual effects. During a model within individual effects, the null is extremely rejected for all variables.

When international cross-correlations are taken into account, the results rely on the specification of these cross-sectional dependencies. The series tests are built on a dynamic factor model by Moon and Perron and opposition to these specifications is dependent on a common factor or time effects. It appears that the consequents are globally and intelligibly better in favor of the unit root assumption for most leading macroeconomic and financial indicators. 
Table 3: Moon and Perron Panel Unit Root Test for All Sample

\begin{tabular}{|l|c|c|c|c|c|c|c|}
\hline Variables & $\hat{\gamma}$ & $t_{a}^{*}$ & $t_{b}^{*}$ & $\hat{p}_{\text {pooi }}^{*}$ & $t_{a}^{* B}$ & $t_{b}^{* B}$ & $\hat{p}_{\text {pooi }}^{* B}$ \\
\hline LRGDP & 5 & -6.471 & -4.179 & 0.749 & -8.250 & -4.861 & 0.717 \\
\hline & & 0.000 & 0.000 & & 0.000 & 0.000 & \\
\hline LLID & 3 & -9.341 & -4.233 & 0.613 & -9.233 & -4.176 & 0.611 \\
\hline & & 0.000 & 0.000 & & 0.000 & 0.000 & \\
\hline LSPRICE & 5 & -8.863 & -5.446 & 0.665 & -9.755 & -5.650 & 0.643 \\
\hline & & 0.000 & 0.000 & & 0.000 & 0.000 & \\
\hline FINCON & 5 & -9.243 & -6.736 & 0.641 & -12.643 & -6.055 & 0.476 \\
\hline & & 0.000 & 0.000 & & 0.000 & 0.000 & \\
\hline UNEMP & 5 & -6.654 & -4.328 & 0.708 & -7.805 & -4.780 & 0.688 \\
\hline & & 0.000 & 0.000 & & 0.000 & 0.000 & \\
\hline LTINT & 5 & -9.544 & -5.499 & 0.625 & -12.557 & -5.911 & 0.525 \\
\hline & & 0.000 & 0.000 & & 0.000 & 0.000 & \\
\hline INFL & 5 & -14.005 & -8.943 & 0.444 & -15.806 & -6.114 & 0.162 \\
\hline & & 0.000 & 0.000 & & 0.000 & 0.000 & \\
\hline FCAPITAL & 4 & -7.315 & -4.240 & 0.696 & -8.225 & -4.713 & 0.691 \\
\hline & & 0.000 & 0.000 & & 0.000 & 0.000 & \\
\hline RQ & 5 & -13.943 & -8.780 & 0.496 & -15.125 & -9.474 & 0.494 \\
\hline & & 0.000 & 0.000 & & 0.000 & 0.000 & \\
\hline
\end{tabular}

Table 4 presents the threshold as well as parameter estimates using regulatory quality (RQ) as the transition variable. In this study, we employ life insurance density and stock market activity as proxies for financial development. The effect of financial development on economic growth differs across different regimes of regulatory quality level. Finance development has a significantly negative impact on economic growth if the soundness of regulatory quality is weak. In contrast, this negative effect of financial development on economic growth becomes significantly positive after a country's regulatory quality exceeds a certain level of threshold. Regarding the effects of other control variables on economic growth, the results are generally consistent with the findings in the growth literature. In sum, the evidence in table 4 reveals that regulatory quality plays an important role in the growth effect of finance development. 
Table 4: Linearity Test and Parameter Estimation for All Sample

\begin{tabular}{|c|c|c|}
\hline Specification & PSTR & \\
\hline Transition variable & RQ & \\
\hline Fisher Test with the null of linearity & $27.724 * * *$ & $(0.000)$ \\
\hline Fisher Test with the null of $\mathrm{r}=1$ & 1.632 & $(0.122)$ \\
\hline VARIABLES & Parameter $\widehat{\boldsymbol{\beta}_{0}}$ & Parameter $\widehat{\beta_{0}}+\widehat{\beta_{1}}$ \\
\hline LLID & 12.7734 & 5.8375 \\
\hline LSPRICE & -3.5844 & 0.9221 \\
\hline FINCON & -3.1163 & -0.9024 \\
\hline UNEMP & 2.4345 & -0.2145 \\
\hline LTINT & 3.2978 & -0.1692 \\
\hline INFL & -3.1065 & -1.0813 \\
\hline FCAPITAL & -5.6645 & 0.9388 \\
\hline Location parameter & & $\mathrm{C} 1=47.6733$ \\
\hline Smooth parameter & & $\gamma 1=0.2364$ \\
\hline Residual sum of squares & & $\mathrm{RSS}=2.1433$ \\
\hline
\end{tabular}

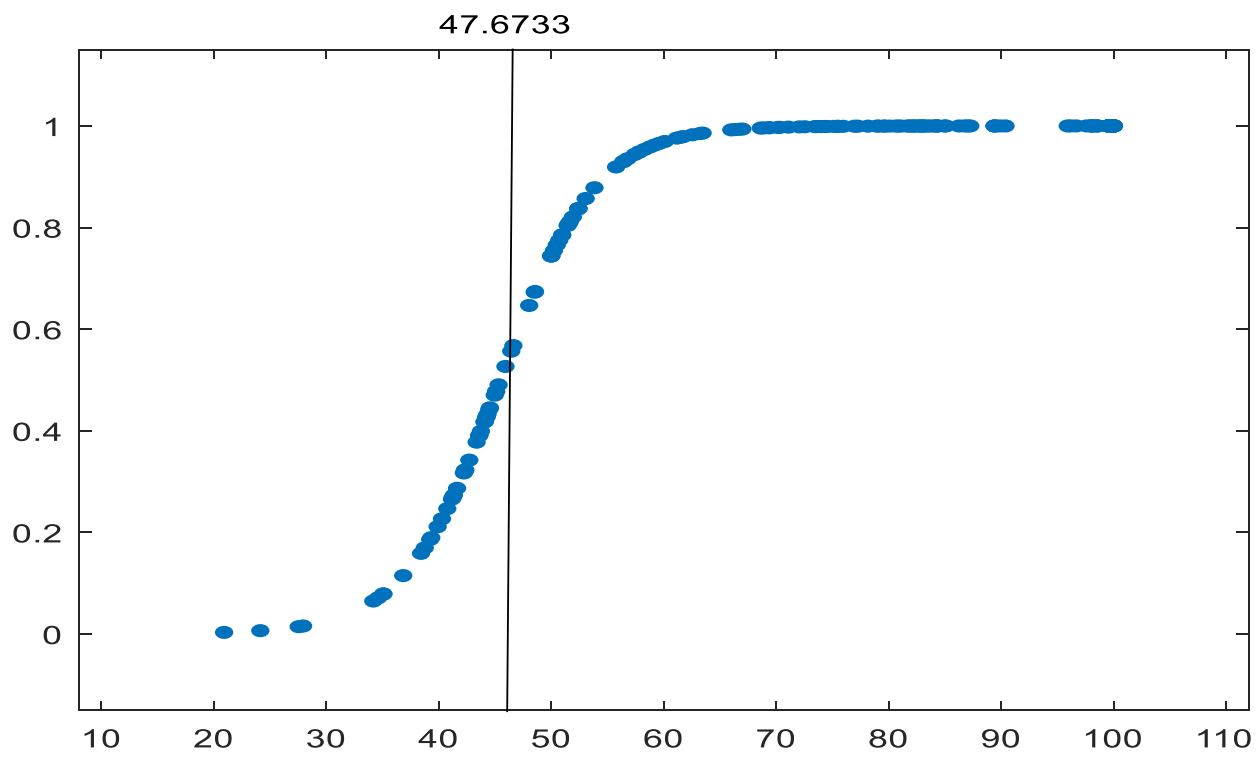

Figure 1: The Transition Function Value for All Sample

Also, Figure 1 depicts the scattered charts showing the changes in the transition function value for all samples in our study. We can tell that the coefficients changed smoothly from weak regulatory quality to strong regimes. From Figure 2, we can see the threshold of regulatory quality is 47.6733 for these Asian countries. Specifically, most of these countries in our sample had reached this level, except 
India and Indonesia. Again, our results imply that economic growth could be harmful because of the problem of adverse selection and moral hazard when lacking a sound regulatory quality environment. On the contrary, when it has achieved a certain level or threshold of regulatory quality, this significantly negative effect becomes positive and significant.

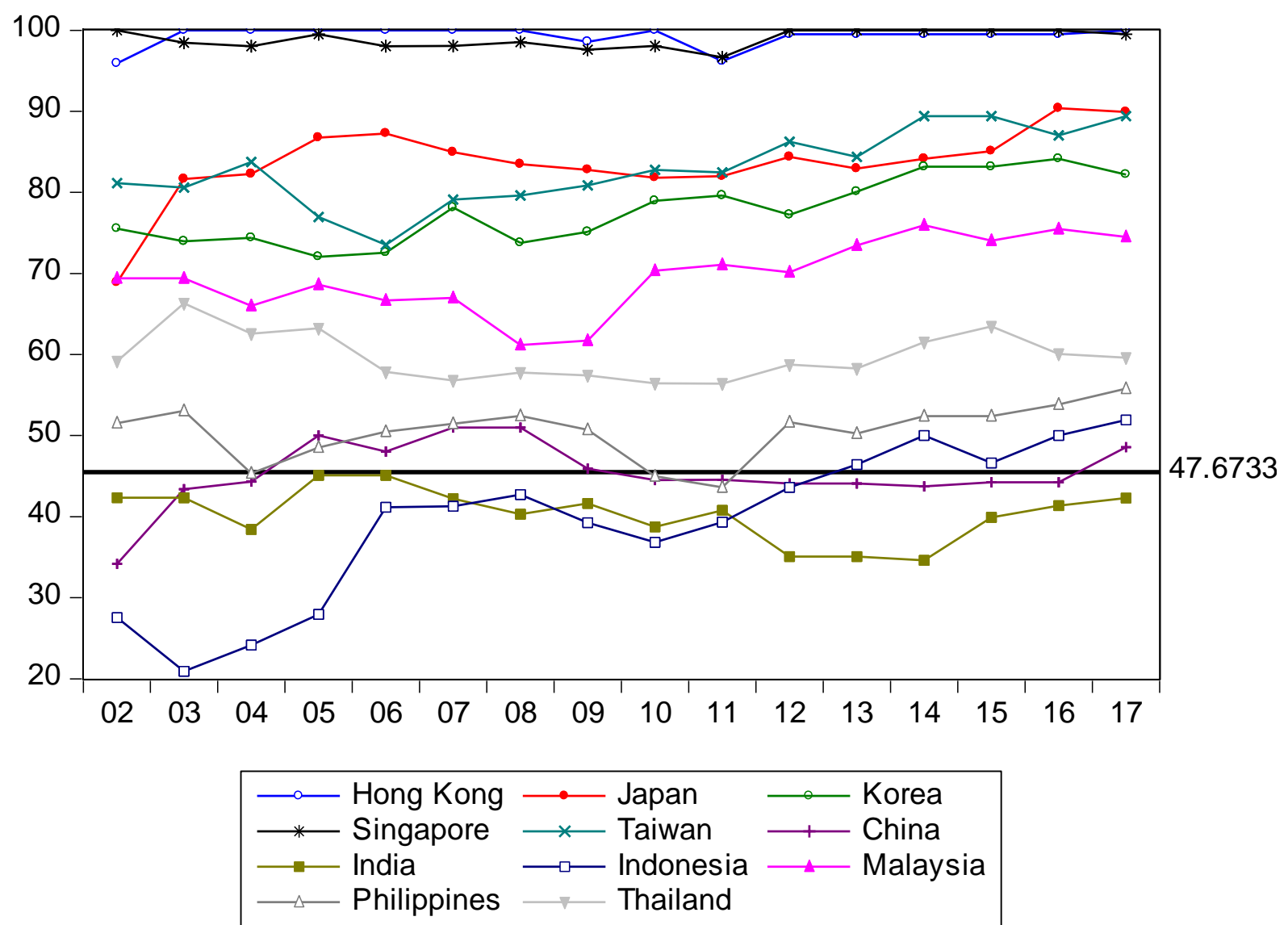

Figure 2: Regulatory Quality for 11 Asian Countries from Years 2002 to 2017 


\section{Conclusion}

The main purpose of this study is to examine whether regulatory quality affects the relationship between financial development and economic growth by applying an innovative panel smooth transition regression (PSTR) model. We investigate the data-set of 11 Asian countries from 2002 to 2017. Our main results demonstrate that the relationship between financial development and economic growth is significantly positive in countries with relatively better regulatory quality.

Overall, our empirical findings send strong signals to governments and administrations of countries in Asia regarding the importance of institutional quality in the economy as well as improving financial development. It not only demonstrates that unhealthy circumstances of regulatory quality could deter economic growth and financial development but also implies that policymakers and authorities should pay particular attention to consider taking some specific measures to improve regulatory quality. For example, control of corruption is crucial for improving regulatory quality. As we know, corruption leads to an inefficient allocation of resources, leading to the high investment cost and low profits of government as well foreign investors. These interesting results and suggestions may provide rich implications for non-Asian economies.

\section{References}

[1] Al-Jarrah, I. M., Al-Zu'bi, M. F., Jaara, O. O., and Alshurideh, M. (2012). Evaluating the impact of financial development on economic growth in Jordan. International Research Journal of Finance and Economics, 94, 123-139.

[2] Ayadi, R., Arbak, E., Naceur, S. B., and De Groen, W. P. (2015). Financial development, bank efficiency, and economic growth across the Mediterranean. In Economic and social development of the Southern and Eastern Mediterranean countries (pp.219-233). Springer.

[3] Avram, K., Nguyen, Y., and Skully, M., (2010). Insurance and Economic Growth: A Cross Country Examination (Working Paper) Monash University.

[4] Bai, J., and $\mathrm{Ng}, \mathrm{S}$., (2004). A panic attack on unit roots and cointegration. Econometrica 72 (4), 1127-1177.

[5] Beck, T., Demirguc-Kunt, A. and Levine, R. (2006). Bank Supervision and Corruption in Lending. Journal of Monetary Economics 53 (8): 2131-2163.

[6] Bick, A., (2010). Threshold effects of inflation on economic growth in developing countries. Econ. Lett. 108 (2), 126-129.

[7] Chen, C. H. and Lee, C. C. (2012). Non-Linearity Between Life Insurance and Economic Development: A Revisited Approach. The Geneva Risk and Insurance Review 37, 223-257.

[8] Chakraborty, I. (2010). Financial development and economic growth in India: An analysis of the post-reform period. South Asia Economic Journal, 11(2), 287-308.

[9] Clague, C., Keefer, P., Knack, S., and Olson, M. (1997). Democracy, autocracy and the institutions supportive of economic growth. In C. Clague (Ed.), 
Institutions and economic development: Growth and governance in less developed and post-socialist countries. Baltimore, MD: John Hopkins University Press.

[10] Dawson, P. J. (2003). Financial development and growth in economies in transition. Applied Economics Letters, 10, 833-836.

[11] Demetriades, P. O., and Law, S. H. (2006). Finance, institutions and financial growth. International Journal of Finance and Economics, 11(3), 245-260.

[12] Din, S. M. U., Abu-Bakar, A. and Regupathi, A. (2017). Does insurance promote economic growth: A comparative study of developed and emerging/developing economies. Cogent Economics and Finance, 5(1), 1-12.

[13] González, A., Teräsvirta, T., and Van Dijk, D. (2005). Panel smooth transition regression models, Research paper 165. Quantitative Finance Research Centre, University of Technology, Sidney.

[14] Granger, C., and Terasvirta, T. (1993). Modelling non-linear economic relationships. OUP Catalogue

[15] Hajamini, M., Falahi, M. A. and Elliott, C. (2014). The nonlinear impact of government consumption expenditure on economic growth: Evidence from low and low-middle income countries. Cogent Economics and Finance, (2).

[16] Hansen, B. E. (1999). Threshold effects in non-dynamic panels: Estimation, testing, and inference. Journal of Econometrics, 93(2), 345-368. https://doi.org/10.1016/S0304-4076(99)00025-1

[17] Hassan, M. K., Sanchez, B., and Yu, J. (2011). Financial development and economic growth: New evidence from panel data. The Quarterly Review of Economics and Finance, 51(1), 88-104.

[18] Hussain, F., and Chakraborty, D. K. (2012). Causality between financial development and economic growth: Evidence from an Indian State. The Romanian Economic Journal, 45, 27-48.

[19] Inoubli, C. (2011). Does financial development impact on growth? Empirical evidence with threshold effect in the MENA region. ERF 17th Annual Conference Paper, Economic research forum.

[20] Jalil, A., and Feridun, M. (2011). Impact of financial development on economic growth: Empirical evidence from Pakistan. Journal of the Asia Pacific Economy, 16(1), 71-80.

[21] King, R. G., and Levine, R. (1993). Finance and growth: Schumpeter might be right. The Quarterly Journal of Economics, 108(3), 717-737.

[22] Lee, K. S. and Werne, R. A. (2018). Reconsidering monetary policy: an empirical examination of the relationship between interest rates and nominal GDP growth in the U.S., U.K. Germany and Japan. Ecological Economics, 146, 26-34.

[23] Lee, C. C., Chang, C.H., Arouri, M. and Lee, C. C. (2016). "Economic Growth and InsuranceDevelopment: The Role of Institutional Environments." Economic Modelling 59: 361-369. 
[24] Masoud, N., and Hardaker, G. (2012). The impact of financial development on economic growth. Studies in Economics \& Finance Studies in Economics and Finance, 29(3), 148-173.

[25] Minier, J. (2003). Are small stock markets different? Journal of Monetary Economics, 50(7), 593-602.

[26] Moon, H. R. and Perron, B. (2004). Testing for a unit root in panels with dynamic factors. Journal of Econometrics, 122, 81-126.

[27] Rajan, R., and Zingales, L. (1998). Financial development and growth. American Economic Review, 88(3), 559-586.

[28] Sahoo, S. (2013). Financial structures and economic development in India: An empirical evaluation. RBI Working Paper Series, WPS (DEPR): 02.

[29] Schumpeter, J. A. (1912). The theory of economic development: An inquiry into profits, capital, credit, interest, and the business cycle. Cambridge, MA: Harvard University Press.

[30] Ward, D., and Zurbruegg, R., (2002). Law, politics and life insurance consumption in Asia. The Geneva Papers on Risk and Insurance 27 (3), 395412.

[31] WDI, 2001. World Development Indicators. The World Bank, Washington, DC. 